\title{
Knockdown of STAT3 expression by RNAi suppresses growth and induces apoptosis and differentiation in glioblastoma stem cells
}

\author{
GUANG-HUI LI ${ }^{1}$, HONG WEI ${ }^{2}$, SHENG-QING LV ${ }^{3}$, HUA JI$^{4}$ and DONG-LIN WANG ${ }^{1,5}$ \\ ${ }^{1}$ Institute for Cancer Research in People's Liberation Army, Xinqiao Hospital, Third Military Medical University, Chongqing \\ 400037; ${ }^{2}$ Department of Plastic Surgery, Southwest Hospital, Third Military Medical University, Chongqing 400038; \\ ${ }^{3}$ Department of Neurosurgery, Xinqiao Hospital, Third Military Medical University, Chongqing 400037; \\ ${ }^{4}$ Department of Oncology, Kunming General Hospital of PLA, Kunming 650032, P.R. China
}

Received February 24, 2010; Accepted April 9, 2010

DOI: 10.3892/ijo_00000658

\begin{abstract}
Glioblastoma is a highly lethal brain tumor of the human primary nervous system tumors. Previous studies demonstrated that glioblastoma stem cells were able to initiate and reform the original cancer. In this study, we found that there were expression and activation of STAT3, a key signal transduction factor and oncoprotein, in human glioblastoma stem cells (GSCs). STAT3 plays a key role in proliferation, apoptosis and differentiation in embryonic stem cells and several cancer types. To investigate the effects of STAT3 on human GSCs, the expression and activation of STAT3 were suppressed by RNAi mediated with lentivirus. We demonstrated that siRNA of STAT3 significantly suppressed STAT3 expression and activation and resulted in inhibition of cell growth in GSCs. Knockdown of STAT3 induces apoptosis and reduces significantly expression of Bcl-2 and cyclin-D in human primary GSCs, whereas no significance was achieved in BAX and caspase-3 expression. Inhibition of STAT3 expression is associated not only with decreasing of $\mathrm{CD} 133^{+}$ cell proportion and increasing of GFAP and MBP exression, but also with decrease of the capacity to initiate a tumor in human primary GSCs. Together, these studies suggest that STAT3 is an important target for human GSCs in regulation of GSCs growth, apoptosis, differentiation and tumorigenic potential.
\end{abstract}

\section{Introduction}

Malignant glioma is the most common malignant central nervous system (CNS) tumor and remains difficult to cure despite advances in surgery and adjuvant therapy (1). A subpopulation of cells within glioblastoma were isolated in several studies (2-4). This subpopulation of cells share many

Correspondence to: Dr Dong-lin Wang, ${ }^{5}$ Present address: Department of Oncology, Sichuan Provincial People's Hospital, Chengdu 610072, P.R. China

E-mail: wdl_tmmu@yahoo.cn

Key words: glioblastoma, cancer stem cell, STAT3, self-renewal, apoptosis characteristics of embryonic stem cells and normal tissue stem cells. The cells possess the ability of initiation, progression and recurrence of cancer $(5,6)$, and was termed cancer stem cells of glioblastoma (GBM). The cancer stem cells of glioblastoma (GSCs) could be a novel therapeutic target in glioblastoma. More and more studies have focused on the characteristics and mechanism of self-renewal and therapeutic resistance in GSCs (7-9).

Signal transducer and activator of transcription 3 (STAT3), a member of STAT protein family, regulates critical cellular processes (10). Recruitment and activation of STAT3 is essential for self-renewal of embryonic stem cells (ESC) $(11,12)$. STAT3 also expresses during the development of the nervous system and regulates the differentiation of neural progenitor cells with synergistical contribution of other signaling cascades $(13,14)$. It stands out by its constitutive phosphorylation in the majority of human neoplasms and its capacity of inducing cell transformation and tumorigenesis $(10,15)$. Several studies found that STAT3 was expressed and was constitutively activated in GBM cell and cell lines. It contributes to promoting tumor cell proliferation and preventing cell death by regulating expression of the context gene (16).

We have isolated GSCs from human primary glioblastoma tissue and identified the characteristics of cancer stem cells (17). Expression and activation of STAT3 were observed in GSCs isolated by us. However, the role of STAT3 in human GSCs is unclear. To observe the effects of STAT3 in glioblastoma stem cells, the expression and activation of STAT3 were knocked downed by lentivirus-mediated RNAi. We found that inhibition of STAT3 expression and activation were able to suppress growth and induce differentiation and apoptosis in human GSCs.

\section{Materials and methods}

Cell culture. Primary GSCs were isolated from 3 tumor samples of human glioblastoma, as approved by the Research Ethics Boards in the Xinqiao Hospital. The characteristics of cancer stem cell were identified in our previous work (17). The GSCs were maintained in NSC (neural stem cell) proliferation medium containing $20 \mathrm{ng} / \mathrm{ml}$ of basic fibroblast 
Table I. Specific primers were used for the amplification of the sequences indicated using the following RT-PCR program: $95^{\circ} \mathrm{C}$ for $5 \mathrm{sec}, 53-60^{\circ} \mathrm{C}$ for $15 \mathrm{sec}$, and $72^{\circ} \mathrm{C}$ for $15 \mathrm{sec}$, with an additional 5 min incubation at $72^{\circ} \mathrm{C}$ after completion of the last cycle.

Real-time PCR primers

\begin{tabular}{llc}
\cline { 2 - 3 } Gene & \multicolumn{1}{c}{ Sequences } & Size of products (bp) \\
\hline STAT3 & 5'-GAGGACTGAGCATCGAGCA-3' & 85 \\
Cyclin D1 & 5'-CATGTGATCTGACACCCTGAA-3' & \\
& 5'-GAAGATCGTCGCCACCTG-3' & 61 \\
Bcl-2 & 5'-GACCTCCTCCTCGCACTTCT-3' & \\
& 5'-CTGGTGGGAGCTTGCATCAC-3' & 149 \\
BAX & 5'-ACAGCCTGCAGCTTTGTTTC-3' & \\
& 5'-GCTGTTGGGCTGGATCCAAG-3' & 138 \\
Caspase-3 & 5'-TCAGCCCATCTTCTTCCAGA-3' & \\
& 5'-CCAGTGGAGGCCGACTTCT-3' & 95 \\
B-actin & 5'-GGAGCCATCCTTTGAATTTCG-3' & \\
& 5'-CCAACCGCGAGAAGATGA-3' & 98 \\
\hline
\end{tabular}

growth factor (bFGF, Peprotech), $20 \mathrm{ng} / \mathrm{ml}$ of epidermal growth factor (EGF, Peprotech) and $20 \mathrm{ng} / \mathrm{ml}$ leukemia inhibitory factor (LIF, Chemicon) (18). The formed tumor spheres of GSCs were then disaggregated and used for culturing or indicated assays.

Immunocytochemical staining for STAT3 and pSTAT3. For immunocytochemical staining of GSCs, tumor sphere cells were plated onto poly-L-ornithine-coated glass in NSC medium for $4 \mathrm{~h}$. Cells were then fixed with $4 \%$ paraformaldehyde and stained with anti-phospho-STAT3 antibodies and anti-STAT3 antibodies (Santa Cruz, USA). Appropriate SP cytostain-plus kits (Zhongshan Biotechnology) were used. Color visualization was performed using 3-3'diaminobenzidine as the chromagen substrate (Zhongshan Biotechnology).

STAT3 silencing in human GSCs. STAT3 was silenced with lentivirus vector that contained ShSTAT3 constructs (5'TAACTTCAGACCCGTCAACAAATTCAAGAGATTTGTT GACGGGTCTGAAGTTTTTTTTC-3') and GFP gene. The produce of lentivirus shSTAT3 vector (pSC-GFP/STAT3) and infection of GSCs were according to the manufacturer's instructions. A control shRNA unrelated to human gene sequences was used as a negative control (pSC-GFP/Con). The infected GSCs were cultured in NSC medium and were used for assays at $72 \mathrm{~h}$ after infected.

Flow cytometry and cell proliferation analysis. GFP were expressed in the GSCs infected with pSC-GFP. The proportion of infected cells was analyzed with FACS. Cell cycle of infected cells was assayed with FACS after cells were stained with propidium iodide (PI, Bender).

The percentage of $\mathrm{CD} 133^{+}$cells and apoptotic cells also were analyzed with FACS. The GSCs were dissociated into single cells and were counted by flow cytometry after stained with CD133-2-phycoerythrin (fluorochrome-conjugated mouse monoclonal IgG1; Miltenyi Biotec) according to the manufacturer's instructions. Apoptotic cells of GSCs were measured with FACS after stained with annexin V-APC (Pharmingen, Germany) and PI according to the manufacturer's instructions. The experiment was repeated three times.

For in vitro cell growth assays, the infected cells were plated in 96-well microwell plates with $0.1 \mathrm{ml}$ NSC medium, at a density of 1000 cells/well. Cell proliferation assays were performed on day $1,3,5,7$ and 9 post-plating using the WST-8 based Colorimetric assay cell counting kit 8 (CCK-8, Dojindo, Japan). Quantification of viable cells through measure the absorbance at $450 \mathrm{~nm}$ using a microplate reader.

Q-PCR and Western blot assay. Total RNA was extracted with Tripure Reagent (Roche, USA). Retrotranscription was carried out with RNA for each sample using RT M-MLV (Toyobo, Japan) in the presence of random primers. Quantitative real-time PCR, using SYBR-Green real-time PCR master mix kit (Toyobo, Japan), was performed according to the manufacturer's protocol (MJ Research, Waltham, MA, USA). STAT3, Bcl-2, BAX, caspase- 3 and cyclin D1 genes were amplified using specific oligonucleotide primers and house-keeping gene, $\beta$-actin, used as internal standard. The sequences of the primers and the size of the products are described in Table I.

The total protein of cell extracts were prepared with Nuclear-Cytosol extraction kit (KeyGen Tec, Nanjing, China), resolved on a $10 \%$ SDS-PAGE, blotted onto a membrane. After blocking at $37^{\circ} \mathrm{C}$ with 5\% milk in PBS containing $0.1 \%$ Tween- 20 for $2 \mathrm{~h}$, membranes were incubated overnight with each antibody as indicated. After extensive washing, immunocomplexes were detected with horseradish peroxidase 
A

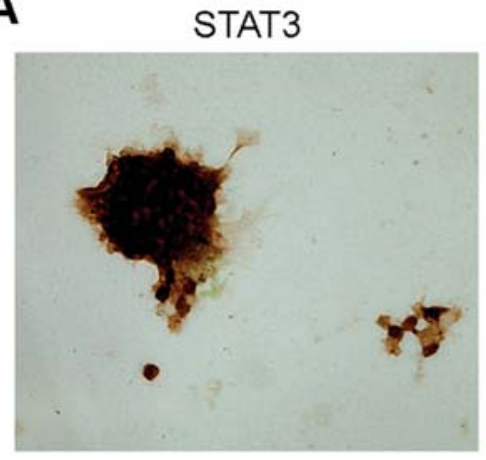

B

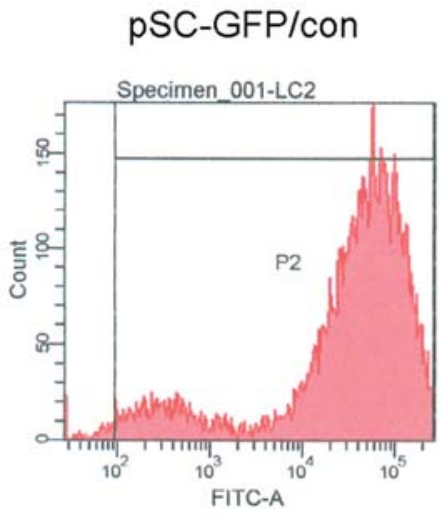

pSTAT3

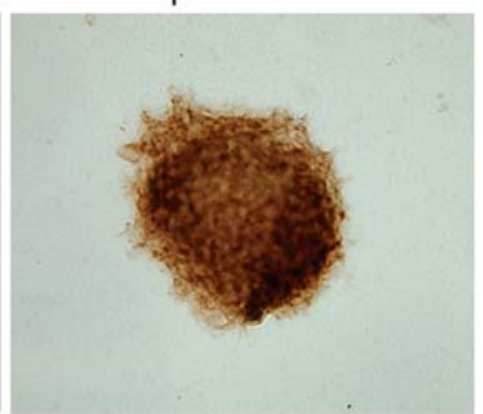

pSC-GFP/STAT3

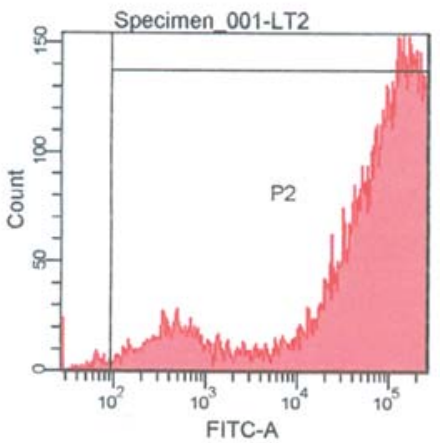

C

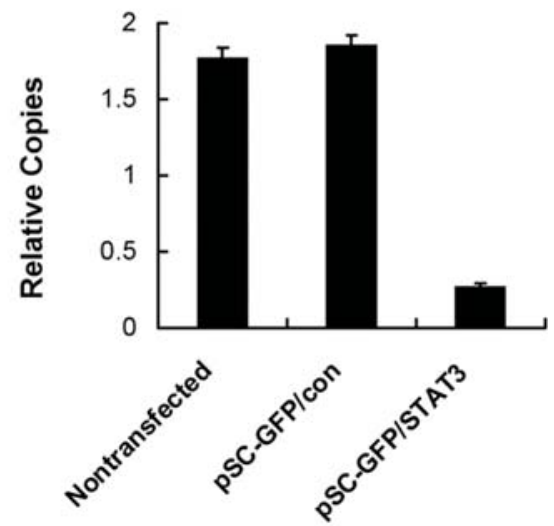

D

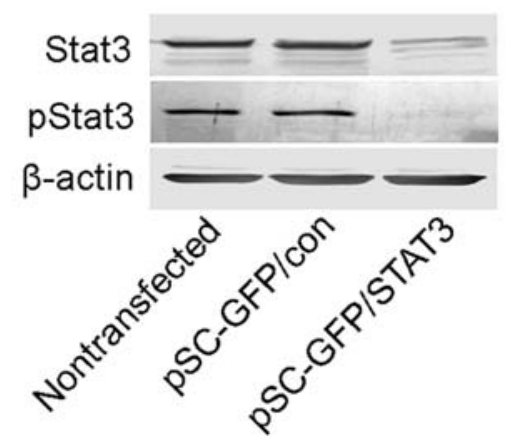

Figure 1. STAT3 and pSTAT3 were analyzed by immunocytochemistry and STAT3 siRNA inhibited the expression and activation of STAT3 in GSCs. STAT3 and pSTAT3 were analyzed with immunocytochemical staining. The cell nucleus and cytoplasm were stained with anti-STAT3 and anti-pSTAT3 antibodies (x400) (A). The proportion of GSCs infected by pSC-GFP/con and p SC-GFP/STAT3 both were 98.6\% (B). Real-time Q-PCR (C) and Western blot (D) was performed to measure the expression and activation of STAT3. STAT3 mRNA, protein and pSTAT3 in GSC cells decreased significantly after treated with STAT3 siRNA $(\mathrm{p}<0.05)$. Each value of PCR represents the mean of nine replicates \pm SD. Bars represent the standard error of the mean. The Western blot experiment of Western blot was repeated twice.

conjugated appropriate secondary antibodies followed by 3-3'-diaminobenzidine as the chromagen substrate. Anticyclin D1, anti-Bcl2, anti-BAX, anti-caspase-3, anti-GFAP, anti-MBP and anti- $\beta$-actin antibodies were obtained from Zhongshan Biotechnology (China).

Transplanting of GSCs in vivo. Five Balb/C nude mice (6 weeks old; The Experimental Animal Laboratories, Shanghai, China) were anesthetized with i.p. ketamine and xylazine and then were treated with VP-16 (etoposide), $30 \mathrm{mg} / \mathrm{kg}$, diluted in serum-free HBSS, via an i.p. injection. Seven days later, the mice were anesthetized as described above, and 10,000 cells infected with pSC-GFP/con and pSCGFP/STAT3 were implanted into left and right subcutaneous of back near upper extremity, respectively. Tumor growth was monitored weekly. The mice were sacrificed at the 8th week after implantation. The same experiment was repeated once with identical conditions. All the animal experiments were performed in strict accordance with the Institutional Animal Care guidelines.

Histology and immunohistochemistry of transplant tumor. Mice were sacrificed. The tissues of the transplant tumor were fixed with formalin. Tissue sections were mounted on microscope slides and stained with Harris hematoxylin and eosin. To characterize the transplant glioblastoma tissue by immunohistochemistry, free-floating sections were treated with bovine serum (Sigma) and stained with primary antibodies for human GFAP (1:100). Subsequent immunodetection was performed using appropriate secondary antibodies (TRITC goat anti-mouse; Santa Cruz Biotechnology) and Hoechst 33342. Then, images were captured using a confocal fluorescence microscope (Leica, Germany).

Statistical analysis. The $\chi^{2}$ analysis was performed to evaluate the significance of inter-group differences. Each experimental point from Q-PCR analysis was measured in triplicate. Values were expressed as the mean \pm SD. Statistical analyses were performed by one-way ANOVA, followed by the Student-Newman-Keuls test for multiple comparisons, with a significance level of $\mathrm{p}<0.05$.

\section{Results}

Expression and constitutive activation of STAT3 in human GSCs. We first examined STAT3 expression and activation by immunocytochemical staining with anti-STAT3 antibody and anti-pSTAT3 antibody. The result showed that there was expression and constitutive activation of STAT3 in human GSCs (Fig. 1A). It was confirmed by the result of real-time Q-PCR and Western blot for STAT3 and pSTAT3 (Fig. 1C and D). 
A

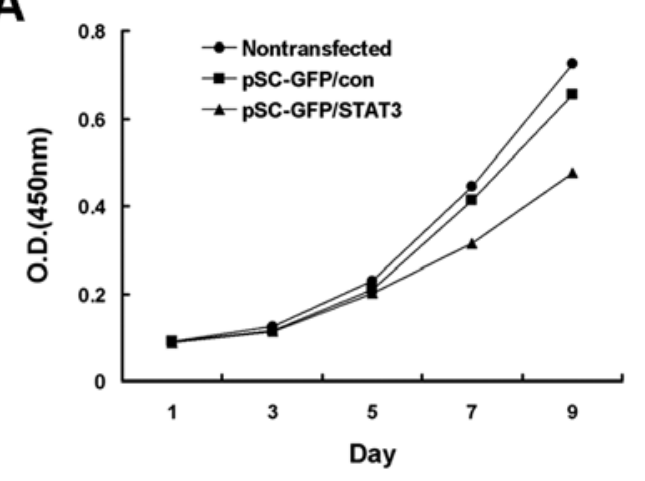

C

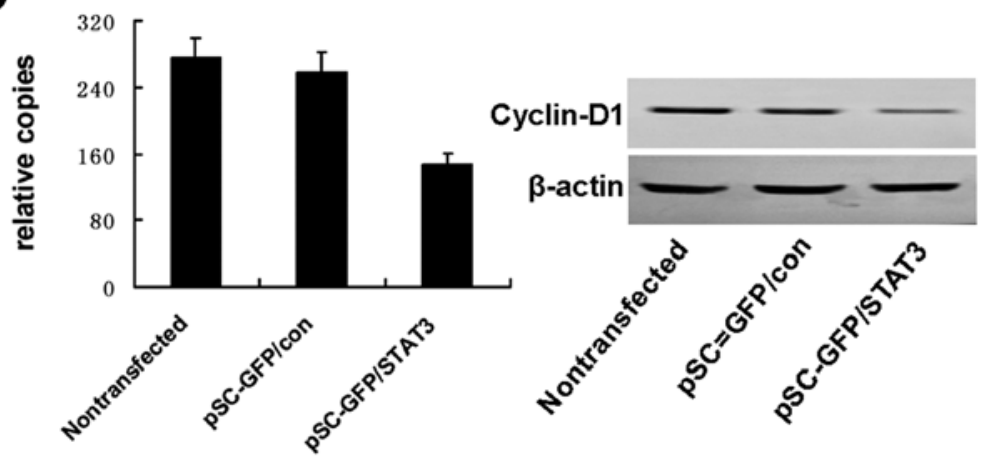

B

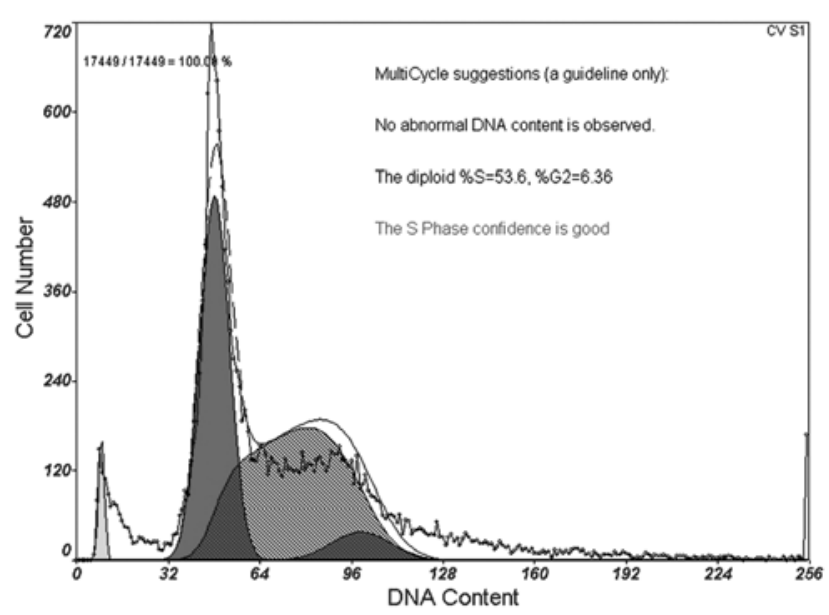

Nontransfected
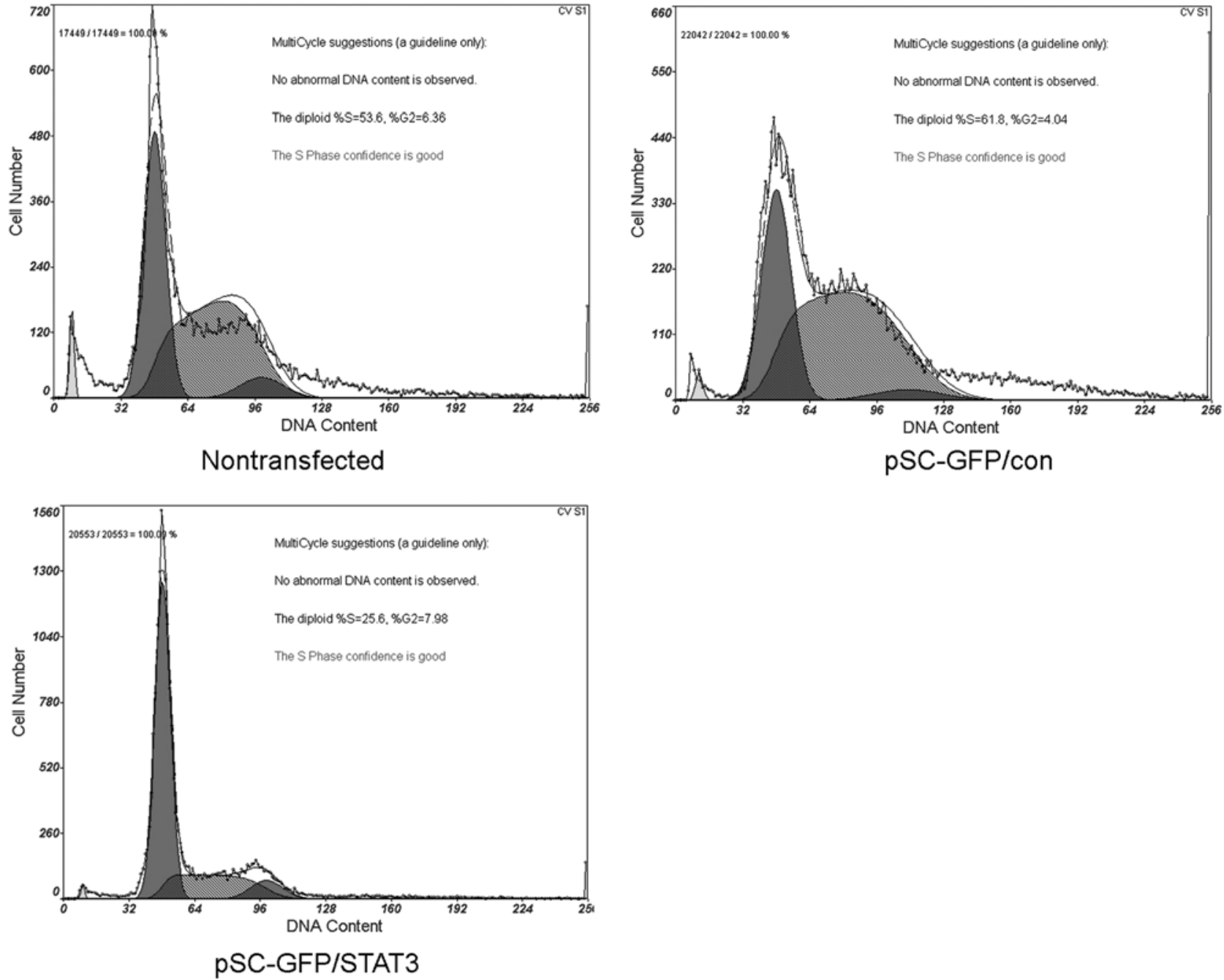

Figure 2. Effects of STAT3 on proliferation, cell cycle and cyclin D1 expression in human GSCs. The proliferation was suppressed (A) and the proportion of G1 significantly increased in GSCs infected by pSC-GFP/STAT3 compared with GSCs without infection and with pSC-GFP/con infecting (p<0.05) (B). Expression of cyclin D1 in GSCs was measured by real-time Q-PCR and Western blot (C). Expression of cyclin D1 in GSCs decreased markedly after STAT3 silencing by RNAi $(\mathrm{p}<0.05)$. Each value of PCR represents the mean of nine replicates \pm SD. Bars represent the standard error of the mean. The Western blot experiment was repeated twice.

STAT3 silencing by RNAi in human GSCs. The result of FACS showed that $98.6 \%$ GSCs expressed GFP at $72 \mathrm{~h}$ after infected with pSC-GFP/con or pSC-GFP/STAT3 (Fig. 1B). RNAi of STAT3 significantly reduced the copies of STAT3 mRNA of GSCs infected with pSC-GFP/STAT3 to $84.3 \%$ of non-transfected GSCs $(\mathrm{p}<0.05)$. There was no significant difference between GSCs without infection and GSCs infected with $\mathrm{pSC}-\mathrm{GFP} / \mathrm{con}$ (Fig. 1C). As shown in the results of Western blot (Fig. 1D), expression and activation of STAT3 was virtually eliminated from GSCs infected with pSC-GFP/ STAT3 compared with GSCs without infection and GSCs infected with $\mathrm{pSC}-\mathrm{GFP} / \mathrm{con}$. It indicated that lentivirus vector 
A
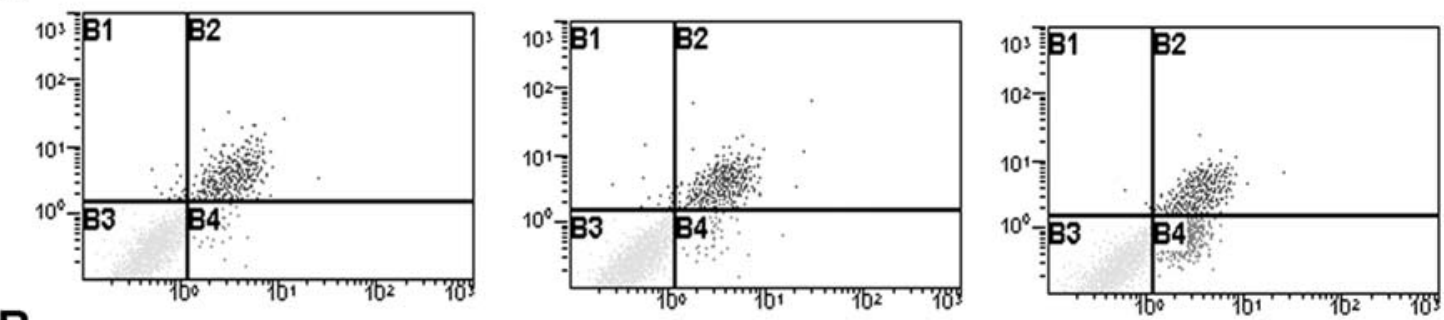

B
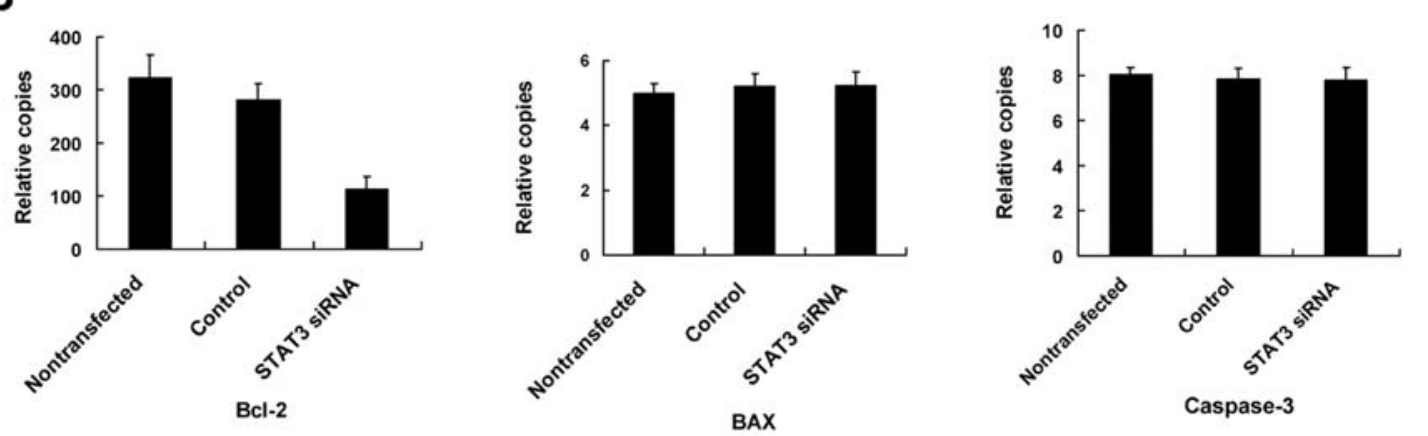

C

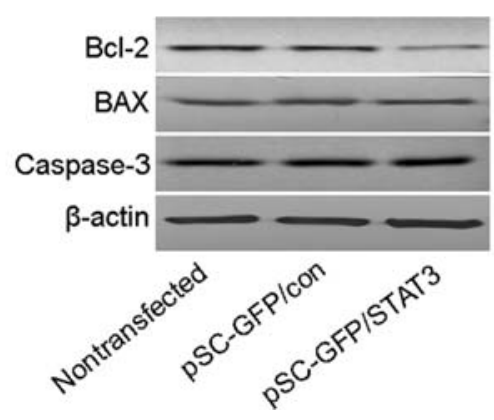

Figure 3. Knockdown of STAT3 expression with RNAi induces apoptosis and downregulates expression of Bcl-2 in human GSCs. Apoptosis of GSCs was analyzed with FACS after cells were immunostained with APC coupled with anti-annexin V antibody. Flow cytometry analysis was performed for each sample in triplicate. The apoptosis rate of GSCs treated with STAT3 siRNA was significantly higher than two control groups (p<0.05) (A). The results of Q-PCR (B) and Western blot (C) showed that Bcl-2 expression decreased significantly in GSCs with STAT3 RNAi compared with the other two groups (p<0.05). No significance was achieved in BAX and caspase-3 expression whether STAT3 expression was inhibited by RNAi or not in GSCs (p $>0.05$ ). Each value of PCR represents the mean of nine replicates \pm SD. Bars represent the standard error of the mean. The Western blot experiment was repeated twice.

of shSTAT3 not only had a high efficiency for infecting GSCs but also was able to inhibit efficiently the expression and activation of STAT3.

Knockdown of STAT3 expression by RNAi inhibits cell growth of GSCs. The effect of STAT3 on proliferation of GSCs was analyzed with CCK-8 assay. The result of proliferation curve showed that GSCs treated with STAT3 siRNA grow significantly slower compared with non-transfected GSCs and GSCs infected with pSC-GFP/con (Fig. 2A). FACS analysis demonstrated that the proportion of $\mathrm{G} 1$ and $\mathrm{S}$ of GSCs infected with pSC-GFP/STAT3 (G1 66.4\%, S 25.6\%) were significantly different compared to non-transfected GSCs (G1 40\%, S 53.6\%) and GSCs infected with pSCGFP/con (G1 34.2\%, S 61.8\%) (p<0.05) (Fig. 2B). Data indicated that STAT3 interfered with the procedure of G1 cell cycle by regulating the expression of cyclin D1 (19). The expression of cyclin D1 in GSCs was assayed with Q-PCR and Western blot. As shown in Fig. 2C, mRNA and protein of cyclin D1 were markedly decreased in GSCs infected with pSC-GFP/STAT3 compared to non-transfected cells $(\mathrm{p}<0.01)$ and $\mathrm{pSC}-\mathrm{GFP} / \mathrm{con}$ infecting cells $(\mathrm{p}<0.01)$. The results suggested that knockdown of STAT3 led to downregulation of cyclin D1 protein in human primary GSCs.

STAT3 silencing induced apoptosis in human GSCs. There were morphologic change and death in cells infected with pSC-GFP/STAT3. It suggested that GSCs infected with shSTAT3 lentivirus might undergo apoptosis. Therefore, we evaluated the effect of STAT3 on apoptosis of GSCs. First, the apoptotic cells in GSCs were stained with annexin VAPC and FACS analysis was performed. The result of FACS indicated that apoptotic rate of cells with STAT3 RNAi $(16.03 \%)$ increased significantly compared with cells infected with pSC-GFP/con (3.19\%) and non-infected GSCs $(2.03 \%)(\mathrm{p}<0.05)($ Fig. 3A). Consistent with this observation, real-time Q-PCR and Western blot were performed to determine the expression of apoptosis gene Bcl-2, BAX and caspase-3 in GSCs. The results showed that Bcl-2 expression decreased significantly in GSCs with STAT3 RNAi compared with cells infected with control siRNA and non-infected cells $(\mathrm{p}<0.01)$ (Fig. $3 \mathrm{~B}$ and $\mathrm{C})$. Whereas no 
A

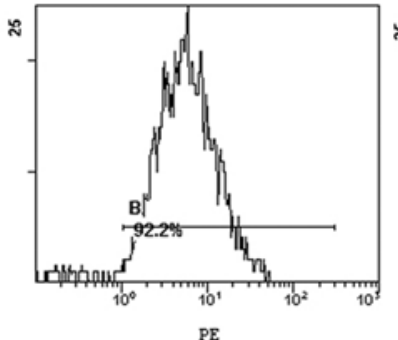

Nontransfected

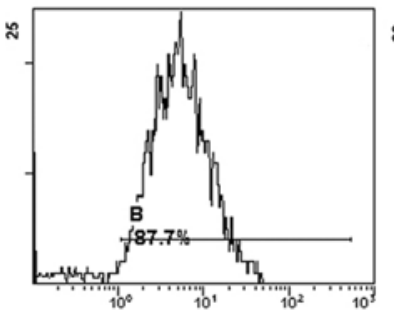

$\mathrm{PE}$ pSC-GFP/con

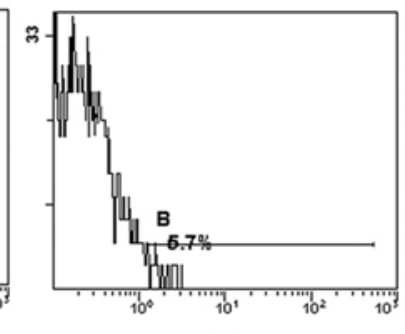

PE pSC-GFPISTAT3
B

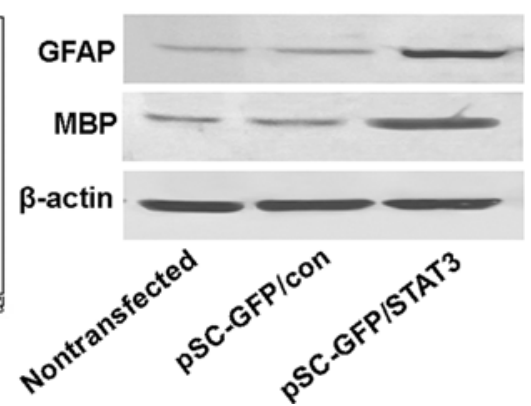

Figure 4. The rate of CD133+ cells were analyzed with FACS (A) and expression of GFAP and MBP was measured with Western blot (B) in GSCs. The proportion of $\mathrm{CD}_{13} 3^{+}$cells in GSCs with STAT3 RNAi (5.7\%) was decreased significantly compared with GSCs without infection (92.2\%) and GSCs with pSC-GFP/con infecting (87.7\%) $(\mathrm{p}<0.05)$. The expression of GFAP and MBP increased significantly in GSCs after STAT3 silencing.

A

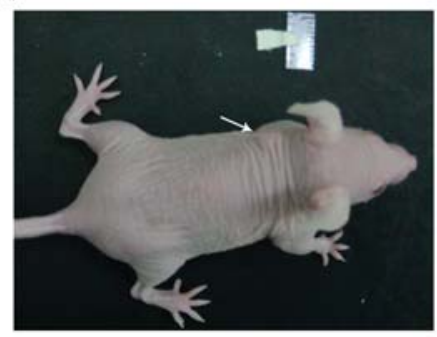

B

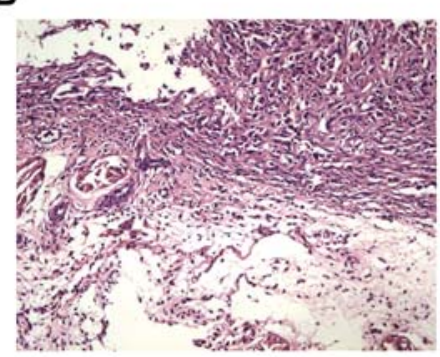

C

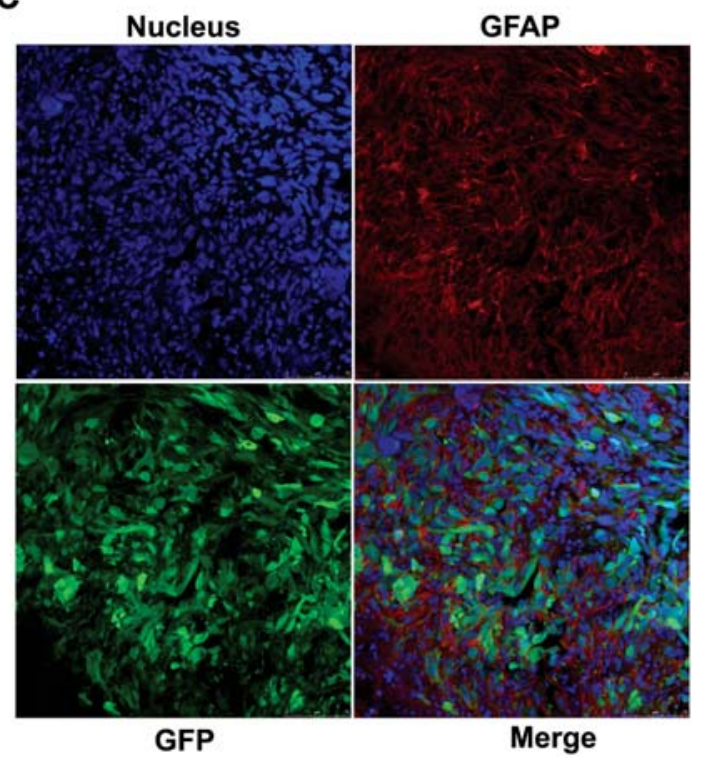

Figure 5. The capacity of in vivo tumor-forming in GSCs after expression of STAT3 was suppressed. The GSCs infected with pSC-GFP/con were able to form tumors in nude mice after subcutaneous implantations (left), but GSCs with STAT3 RNAi did not (right) (A). The tumors developed in the mice were stained by hematoxylin and eosin (B) and the immunofluorescence analysis showed that the transplanting tumor tissue could be stained with human-specific antibodies against GFAP (nucleus, blue; GFAP, red; GFP, green) (C).

significance was achieved in BAX and caspase-3 expression whether STAT3 expression was inhibited by RNAi or not in GSCs $(p>0.05)$. Together these data indicated that STAT3 regulated an anti-apoptotic program in human GSCs and knockdown of STAT3 induced apoptosis of human GSCs.

STAT3 RNAi induces differentiation and inhibits tumorigenesis of human primary GSCs in vivo. CD133, a cell surface marker for human neural stem cells, is widely accepted as marker for glioblastoma stem cells (20). The GSCs will lose expression of CD133 and exhibit immunoreactivity for differentiated neural cell marker such as GFAP, MBP and MAP2 when they begin to differentiate $(2,3)$. The proportion of $\mathrm{CD}_{133}{ }^{+}$cells were $92.2,87.7$ and $5.7 \%$ in non-transfected GSCs, control siRNA infecting cells and STAT3 siRNA infecting cells, respectively (Fig. 4A). The CD133+ cells significantly decreased in GSCs after infected with pSC-
GFP/STAT3 $(p<0.05)$. The result of Western blot showed that expression of GFAP and MBP increased significantly in GSCs after STAT3 RNAi (Fig. 4B).

Our previous study showed that the transplant tumor formed in vivo after implanting 1,000-10,000 GSC cells subcutaneously into nude mice (17). To observe the ability of initiating tumor in vivo after knockdown of STAT3 expression in human GSCs, 10,000 cells infected with pSCGFP/STAT3 or pSC-GFP/con per mouse were implanted into nude mice. Transplanted tumor formed in 3 nude mice with implantation of $\mathrm{pSC}-\mathrm{GFP} / \mathrm{con}$ infected cells, but no tumor formed in 5 mice with implantation of cells with STAT3 silencing. The transplanted glioblastoma was characterized by $\mathrm{H} \& \mathrm{E}$ staining and immunohistochemistry for GFAP in tumor tissue sections (Fig. 5). These results suggested that knockdown of STAT3 expression in GSCs suppressed the capacity to initiate a tumor in vivo. 


\section{Discussion}

GSCs, as other cancer stem cells, are widely thought to be able to initiate and reform the original cancer after they were isolated and identified from primary tumor tissue (21). They have many different characteristics compared to nontumorigenic cells and have stronger ability against chemotherapy and radiotherapy compared with the non-tumorigenic cells. GSCs possess the property of multipotential differentiation, unlimited proliferation and self-renewal. The mechanism of self-renewal in GSCs plays an important role of maintaining characteristics of cancer stem cells $(2,3,5$, 7,22-24).

STAT3 is required for self-renewal of embryonic stem cell and development of the nervous system (10). Expression and activation of STAT3 were found frequently in human GBM and GBM cell lines. Our data demonstrated that there was expression and activation of STAT3 in human GSCs. Nilsson et al also identified the expression and activation of STAT3 in GSCs (25). Many studies indicated that it acted by promoting proliferation, anti-apoptosis and cell cycle progression $(10,26,27)$. However, recent data indicated that inhibiting expression of STAT3 promoted the proliferation and invasiveness of human GBM cells $(28,29)$. Which role does STAT3 play in human GSCs? RNAi mediated with retroviral vector is an attractive tool to explore the effect of STAT3 on GSCs. The results of FACS, PCR and Western blot indicated that the lentivirus vector had a high efficiency to infect GSCs, and STAT3 siRNA not only knocked downed the expression of STAT3 but also suppressed the activation of STAT3.

GSCs had a significant change in growth and morphology after infection with STAT3 siRNA vector. First, the growth of GSCs was analyzed by CCK-8 kit after STAT3 silencing. The result suggested that knockdown of STAT3 expression suppressed significantly growth of human GSCs. Flow cytometry analysis demonstrated that the proportion of $\mathrm{G} 1$ increased significantly in GSCs with STAT3 RNAi compared with the two control groups. It suggested that inhibition of STAT3 expression and activation induced G1 arrest in human GSCs. The expression of cyclin D1, which associates with CDK4 or CDK6, controls progression from G1 to S phase of cells (30). Then, the expression of cyclin D1 was analyzed in three groups of GSCs. Q-PCR and Western blot analysis showed that the expression of cyclin D1 significantly reduced in GSCs with STAT3 silencing. The results suggested that suppression of growth and G1 arresting induced by STAT3 silencing might be correlated with the downregulation of cyclin D1 in human GSCs. STAT3 promoted proliferation in our study.

One mechanism by which STAT3 participates in tumorigenesis is by inhibing apoptosis through the induction of anti-apoptotic genes. Many studies have demonstrated that inhibition of STAT3 signaling induced apoptosis in several types of tumor cells (31-34). The apoptotic rate of GSCs with STAT3 RNAi increased significantly in our study. Accumulating data have shown that apoptotic genes such as Bcl-2 were overexpressed in glioblastoma cells and overexpression of these genes were sufficient to block apoptosis in tumor cells (35). STAT3 responsive elements also were found in the promotor region of these genes $(36,37)$. In the present study, expression of Bcl-2, BAX and caspase- 3 were assayed in GSCs with Q-PCR and Western blot. We have found that treating GSCs with STAT3 siRNA significantly reduced expression of $\mathrm{Bcl}-2$, but did not intervene in expression of BAX and caspase-3. It suggests that apoptosis of GSCs induced by STAT3 silencing was mediated with downregulation of Bcl-2 expression.

CD133 is a neural stem cell marker and brain tumor stem cells marker $(38,39)$. The characteristics of cancer stem cells were identified in $\mathrm{CD}_{133^{+}}$human glioblastoma cells isolated by us in the previous study (17). In order to determine the role of STAT3 in self-renewal of human GSCs, we measured the proportion of $\mathrm{CD} 133^{+}$cells in GSCs after inhibiting expression of STAT3. The result of FACS showed that the proportion of $\mathrm{CD} 133^{+}$cells decreased significantly in GSCs with STAT3 RNAi. The markers of differentiation to nerve cells were analyzed in GSCs for further evidence on the effect of STAT3 on differentiation. GFAP (for astrocytes) and MBP (for oligodendrocytes) expression of cells increased significantly after GSC infection by the STAT3 siRNA lentivirus vector. It indicated that GSCs differentiated after treating with STAT3 siRNA and STAT3 played an important role of self-renewal in human GSCs. Sherry et al demonstrated that STAT3 was required for proliferation and maintenance of multipotency in glioblastoma stem cells (40). These results are consistent with ours. The capacity of initiating a tumor is a key characterestic of cancer stem cells. Therefore, we transplanted the tumor into nude mice. The results showed that the ability of GSCs to initiate tumor decreased significantly after the expression of STAT3 was suppressed.

In conclusion, we have identified that knockdown of STAT3 expression inhibited growth and induced G1 arrest and apoptosis in human primary GSCs. The G1 arrest and apoptosis may be correlated with downregulation of cyclin D1 and Bcl-2 mediated by STAT3. Most importantly, inhibition of STAT3 expression may induce differentiation and reduced the ability of initiating a tumor in GSCs. Targeting STAT3 could become an effective therapeutic strategy for human GBM with constitutive expression and activation of STAT3.

\section{Acknowledgments}

This work was supported by the National Natural Science Foundation of China (No. 30973074) and Natural Science Foundation Project of CQ (CSTC. 2009BB5152).

\section{References}

1. Furnari FB, Fenton T, Bachoo RM, Mukasa A, Stommel JM, Stegh A, Hahn WC, Ligon KL, Louis DN, Brennan C, Chin L, DePinho RA and Cavenee WK: Malignant astrocytic glioma: Genetics, biology, and paths to treatment. Genes Dev 21: 2683-2710, 2007.

2. Singh SK, Clarke I, Terasaki M, Bonn V, Hawkins C, Squire J and Dirks P: Identification of a cancer stem cell in human brain tumors. Cancer Res 63: 5821-5828, 2003.

3. Yuan X, Curtin J, Xiong Y, Liu G, Waschsmann-Hogiu S, Farkas DL, Black KL and Yu JS: Isolation of cancer stem cells from adult glioblastoma multiforme. Oncogene 23: 9392-9400, 2004. 
4. Yu S, Ping Y, Yi L, Zhou Z, Chen J, Yao X, Gao L, Wang J and Bian $\mathrm{X}$ : Isolation and characterization of cancer stem cells from a human gliobalstoma cell line U87. Cancer Lett 265: 124-134, 2008.

5. Altaner C: Glioblastoma and stem cells. Neoplasma 55: 369-374, 2008

6. Das S, Srikanth M and Kessler JA: Cancer stem cells and glioma. Nat Clin Pract Neurol 4: 427-435, 2008

7. Eyler CE and Rich JN: Survival of the fittest: cancer stem cells in therapeutic resistance and angiogenesis. J Clin Oncol 26: 2839-2845, 2008.

8. Bertrand J, Begaud-Grimaud G, Bessette B, Verdier M, Battu S and Jauberteau MO: Cancer stem cells from human glioma cell line are resistant to Fas-induced apoptosis. Int J Oncol 34 : 717-727, 2009.

9. Zheng H, Ying H, Yan H, Kimmelman AC, Hiller DJ, Chen AJ, Perry SR, Tonon G, Chu GC, Ding Z, Stommel JM, Dunn KL, Wiedemeyer R, You MJ, Brennan C, Wang YA, Ligon KL, Wong WH, Chin L and Depinho RA: PTEN and p53 converge on c-Myc to control differentiation, self-renewal, and transformation of normal and neoplastic stem cells in glioblastoma. Cold Spring Harb Symp Quant Biol 73: 427-437, 2008.

10. Levy DE and Lee CK: What does STAT3 do? J Clin Invest 109: 1143-1148, 2002.

11. Niwa H, Burdon T, Chambers I and Smith A: Self-renewal of pluripotent embryonic stem cells is mediated via activation of STAT3. Genes Dev 12: 2048-2060, 1998.

12. Ernst M, Novak U, Nicholson SE, Layton JE and Dunn AR: The carboxyl-terminal domains of gp130-related cytokine receptors are necessary for suppressing embryonic stem cell differentiation. Involvement of STAT3. J Biol Chem 274: 9729-9737, 1999.

13. Miao T, Wu D, Zhang Y, Bo X, Subang MC, Wang $\mathrm{P}$ and Richardson PM: Suppressor of cytokine signaling-3 suppresses the ability of activated signal transducer and activator of transcription-3 to stimulate neurite growth in rat primary sensory neurons. J Neurosci 26: 9512-9519, 2006.

14. Schweizer U, Gunnersen J, Karch C, Wiese S, Holtmann B, Takeda K, Akira S and Sendtner M: Conditional gene ablation of STAT3 reveals differential signaling requirements for survival of motoneurons during development and after nerve injury in the adult. J Cell Biol 156: 287-297, 2002.

15. Alvarez JV and Frank DA: Genome-wide analysis of STAT target genes: elucidating the mechanism of STAT-mediated oncogenesis. Cancer Biol Ther 3: 1045-1050, 2004.

16. Rahaman SO, Vogelbaum MA and Haque SJ: Aberrant STAT3 signaling by interleukin-4 in malignant glioma cells: involvement of IL-13R 2 2. Cancer Res 65: 2956-2963, 2005.

17. Li GH, Wang DL, Chen ZT, Yin CL, Ji H and Lv SQ: Isolation and identification of cancer stem cells in human gliomas. Chin J Cancer Prev Treat 14: 37-40, 2007.

18. Reynolds BA and Weiss S: Generation of neurons and astrocytes from isolated cells of the adult mammalian central nervous system. Science 255: 1707-1710, 1992

19. Shields BJ and Tiganis T: Replication checkpoint control by a PTK/STAT3/cyclin D1 axis. Cell Cycle 8: 223-230, 2009.

20. Bidlingmaier $S$, Zhu $X$ and Liu B: The utility and limitations of glycosylated human CD133 epitopes in defining cancer stem cells. J Mol Med 86: 1025-1032, 2008.

21. Soltysova A, Altanerova V and Altaner C: Cancer stem cells. Neoplasma 52: 435-440, 2005.

22. Shervington $\mathrm{A}$ and $\mathrm{Lu} \mathrm{C}$ : Expression of multidrug resistance genes in normal and cancer stem cells. Cancer Invest 26: 535-542, 2008

23. Chalmers AJ: Radioresistant glioma stem cells - therapeutic obstacle or promising target? DNA Repair (Amst) 6: 1391-1394, 2007.
24. Rich JN: Cancer stem cells in radiation resistance. Cancer Res 67: 8980-8984, 2007

25. Nilsson CL, Dillon R, Devakumar A, Shi SD, Greig M, Rogers JC, Krastins B, Rosenblatt M, Kilmer G, Major M, Kaboord BJ, Sarracino D, Rezai T, Prakash A, Lopez M, Ji Y, Priebe W, Lang FF, Colman $\mathrm{H}$ and Conrad CA: Quantitative phosphoproteomic analysis of the STAT3/IL-6/HIF1alpha signaling network: An initial study in GSC11 glioblastoma stem cells. J Proteome Res 9: 430-443, 2010.

26. Bromberg JF, Wrzeszczynska MH, Devgan G, Zhao Y, Pestell RG, Albanese C and Darnell JE Jr: STAT3 as an oncogene. Cell 98: 295-303, 1999

27. Gao SP, Mark KG, Leslie K, Pao W, Motoi N, Gerald WL, Travis WD, Bornmann W, Veach D, Clarkson B and Bromberg JF: Mutations in the EGFR kinase domain mediate STAT3 activation via IL-6 production in human lung adenocarcinomas. J Clin Invest 117: 3846-3856, 2007.

28. de la Iglesia N, Konopka G, Puram SV, Chan JA, Bachoo RM, You MJ, Levy DE, Depinho RA and Bonni A: Identification of a PTEN-regulated STAT3 brain tumor suppressor pathway. Genes Dev 22: 449-462, 2008.

29. de la Iglesia N, Konopka G, Lim KL, Nutt CL, Bromberg JF Frank DA, Mischel PS, Louis DN and Bonni A: Deregulation of a STAT3-interleukin 8 signaling pathway promotes human glioblastoma cell proliferation and invasiveness. J Neurosci 28: 5870-5878, 2008.

30. Sherr CJ and Roberts JM: CDK inhibitors: positive and negative regulators of G1-phase progression. Genes Dev 13: 1501-1512, 1999.

31. Riffkin CD, Gray AZ, Hawkins CJ, Chow CW and Ashley DM: Ex vivo pediatric brain tumors express Fas (CD95) and FasL (CD95L) and are resistant to apoptosis induction. Neuro Oncol 3: 229-240, 2001

32. Grandis JR, Drenning SD, Zeng Q, Watkins SC, Melhem MF, Endo S, Johnson DE, Huang L, He Y and Kim JD: Constitutive activation of that STAT3 signaling abrogates apoptosis in squamous cell carcinogenesis in vivo. Proc Natl Acad Sci USA 97: 4227-4232, 2000.

33. Gao LF, Wen LJ, Yu H, Zhang L, Meng Y, Shao YT, Xu DQ and Zhao XJ: Inhibition of STAT3 expression by siRNA suppresses growth and induces apoptosis in laryngeal cancer cells. Acta Pharmacol Sin 27: 347-352, 2006.

34. Lee SO, Lou W, Qureshi KM, Mehraein-Ghomi F, Trump DL and Gao AC: RNA interference targeting STAT3 inhibits growth and induces apoptosis of human prostate cancer cells. Prostate 60: 303-309, 2004.

35. Scott S, Higdon R, Beckett L, Shi XB, deVere White RW, Earle JD and Gumerlock PH: Bcl2 antisense reduces prostate cancer cell survival following irradiation. Cancer Biother Radiopharm 17: 647-656, 2002.

36. Catlett-Falcone R, Landowski TH, Oshiro MM, Turkson J, Levitzki A, Savino R, Ciliberto G, Moscinski L, FernándezLuna JL, Nuñez G, Dalton WS and Jove R: Constitutive activation of STAT3 signaling confers resistance to apoptosis in human U266 myeloma cells. Immunity 10: 105-115, 1999.

37. Aoki Y, Feldman GM and Tosato G: Inhibition of STAT3 signaling induces apoptosis and decreases survivin expression in primary effusion lymphoma. Blood 101: 1535-1542, 2003.

38. Uchida N, Buck DW, He D, Reitsma MJ, Masek M, Phan TV, Tsukamoto AS, Gage FH and Weissman IL: Direct isolation of human central nervous system stem cells. Proc Natl Acad Sci USA 97: 14720-14725, 2000.

39. Mizrak D, Brittan M and Alison MR: CD133: molecule of the moment. J Pathol 214: 3-9, 2008.

40. Sherry MM, Reeves A, Wu JK and Cochran BH: STAT3 is required for proliferation and maintenance of multipotency in glioblastoma stem cells. Stem Cells 27: 2383-2392, 2009 